\title{
Perbandingan Berbagai Mode/ Conditionally Heteroscedastic Time Series Dalam Analisis Risiko Investasi Saham Syariah Dengan Metode Value At Risk
}

\author{
Mohammad Farhan Qudratullah \\ Program Studi Matematika Fakultas Sains dan Teknologi, UIN Sunan Kalijaga, Jl. Marsda Adisucipto \\ No. 1 Yogyakarta, Indonesia
}

Korespondensi; Email: aching_lo@yahoo.com

\begin{abstract}
Abstrak
Value at Risk (VaR) merupakan salah satu alat yang direkomendasikan Bank Indonesia untuk mengukur resiko suatu investasi, pendekatan VaR yang konvensional cenderung lebih terkait dengan asumsi distribusi normal, sementara penemuan empiris kontemporer menunjukkan adanya pola ketaknormalan dalam sifat statistika data, khususnya pada data keuangan. Sampai dengan saat ini saham-saham yang tergabung dalam Jakarta Islamic Index (JII) masih sangat dipengaruhi oleh dinamisasi pasar yang salah satunya volatilitas, sehingga perlu analisis mendalam untuk membantu investor membuat keputusan yang tepat dalam berinvestasi. Peneliti ini membahas masalah analisis model resiko mengunakan VaR menggunakan berbagai pendekatan model Conditional Heterokedastic Timeseris (CHT) dan menemukan model terbaik. Adapun data yang digunakan adalah data indeks penutupan harian sahamsaham syariah (JII) pasca krisis global 2008 (Januari 2009 - Juni 2011) dan software yang digunakan adalah EViews 5.1 dan Excel 2007. Hasil yang diperoleh adalah dari 16 (enam belas) model pendekatan VaR-CHT yang digunakan, hanya 5 (lima) model yang valid pada tingkat kepercayaan 99\%, yaitu Pendekatan GARCH(2,2), GARCH M Standar Deviasi (1,1), GARCH M Log (Variansi)(1,1), TARCH M Log (Variansi) (1,1), dan EGARCH M Log (Variansi) $(1,1)$. Model VaR CHT yang terbaik dan direkomendasikan dalam menganalisis resiko investasi saham syariah (JII) adalah model yang memberikan nilai VaR terkecil, yaitu model VaR GARCH-M Standar Deviasi (1,1) yang memberikan nilai VaR sebesar $3.2396 \%$.
\end{abstract}

Kata Kunci: Conditional Heterokedastic Timeseris (CHT); GARCH-M; Jakarta Islamic Index (JII); Value at Risk $(\mathrm{VaR})$

\begin{abstract}
Value at Risk (VaR) is one of the tools recommended by Bank Indonesia to measure the risk of an investment, the conventional VaR approach tends to be more closely related to normal distribution assumptions, while contemporary empirical findings suggest a pattern of abnormalities in the statistical properties of data, especially in financial data. Until now the stocks incorporated in the Jakarta Islamic Index (JII) are still heavily influenced by the dynamics of the market which one of them is volatility, so it needs an in-depth analysis to help investors make the right decision in investing. The researcher discusses the problem of risk model analysis using VaR using various approaches of Conditional Heterokedastic Timeseris (CHT) model and finding the best model. The data used is the daily closing index of Sharia stocks (JII) after the global crisis of 2008 (January 2009 - June 2011) and the software used is E-Views 5.1 and Excel 2007. The results obtained are from 16 (sixteen) VRR-CHT approach model used, only 5 (five) valid models at 99\% confidence level, ie GARCH Approach (2.2), GARCH M Standard Deviation (1,1), GARCH M Log (Variance) (1.1), TARCH M Log (Variansi) $(1,1)$, and EGARCH M Log (Variansi) $(1,1)$. The best and recommended VaR CHT model in analyzing Sharia Shares investment risk (JII) is the model that gives the smallest VaR value, the VaR GARCH-M Standard Deviation $(1,1)$ model which gives VaR value $3,2396 \%$.
\end{abstract}

Keywords: Conditional Heterokedastic Timeseris (CHT); GARCH-M; Jakarta Islamic Index (JII); Value at Risk $(\mathrm{VaR})$ 


\section{Pendahuluan}

Sejak PT. Bursa Efek Indonesia (BEI) memperkenalkan pasar modal syariah pada tahun 2000, Badan Pengawas Pasar Modal dan Lembaga Keuangan (BAPEPAM \& LK) mengungkapkan bahwa pasar modal syariah di Indonesia mengalami peningkatan yang signifikan. Secara umum diakhir tahun 2007 kinerja indeks saham syariah yang diukur menggunakan Jakarta Islamic Index (JII) lebih baik dari Indeks Harga Saham Gabungan (IHSG) dan indeks LQ 45. JII menunjukkan trend yang naik, terlihat dari pertumbuhan indeks sebesar 63,4\% dari akhir 2006 sampai 10 desember 2007. Sementara indeks LQ45 hanya $58,77 \%$. Sedangkan untuk seluruh indeks yang tergabung dalam IHSG mencapai angka 54,54\% [6].

Seperti investasi pasar modal pada umumnya, investasi saham syariah memiliki sifat high risk high return, jika tidak hati-hati dapat menyebabkan kebangkrutan bagi investor sehingga perlu managemen resiko. Salah satu langkah penting dalam managemen resiko adalah perhitungan resiko, alat untuk mengukur resiko yang popular bagi pelaku bisnis keuangan dan juga direkomendasikan Bank Indonesia adalah Value at Risk (VaR). Pada penerapannya, pengunaan VaR untuk mengukur resiko pasar sering mengasumsikan data berdistribusi normal, padahal kenyataannya banyak data keuangan sifat-sifat statistiknya menunjukan gejala ketidaknormalan [8]. Qudratullah mengungkapkan bahwa data return JII menunjukan gejala ketidaknormalan, yaitu terdapat penebalan pada ekor distribusi (excess kurtosis yang bersifat heavy tailed) serta menemukan bahwa model Students-T Value at Risk (T-VaR) lebih baik dibanding Normal-VaR dan Lognormal-VaR [7].

Tulisan ini merupakan pengemangan model VaR untuk data return JII dengan mempertimbangkan bahwa data merupakan jenis data timeseries dengan asumsi residua/ bersifat heterokedastisitas, sehingga tulisan ini akan membandingkan berbagai model Conditionally Heteroscedastic Timeseries yang meliputi: Autoregressive Conditional Heteroscedastic (ARCH)/ Generalized Autoregressive Conditional Heteroscedastic (GARCH), ARCH/GARCH-M, Threshold Autoregressive Conditional Heteroscedastic (TARCH), TARCH-M, Exponential Generalized Autoregressive Conditional Heteroscedastic (EGARCH), EGARCH-M, Power Autoregressive Conditional Heteroscedastic (PARCH), dan PARCH-M.

\section{Landasan Teori}

\section{Pasar Modal Syariah di Indonesia}

Pada tanggal 3 Juli 2000, PT Bursa Efek Indonesia bekerjasama dengan PT Danareksa Invesment Management (DIM) meluncurkan indeks saham yang dibuat berdasarkan syariah Islam, yaitu Jakarta Islamic Index (JII). Indeks ini diharapkan menjadi tolak ukur kinerja saham-saham yang berbasis syariah serta untuk lebih mengembangkan pasar modal syariah. JII terdiri atas 30 saham yang terpilih dari saham-saham yang sesuai dengan syariah Islam yang pemilihan sahamnya dilakukan oleh BappepamLK bekerjasama dengan Dewan Syariah Nasional (DSN) setiap 6 bulan melalui 2 tahap, yaitu seleksi syariah dan seleksi nilai volume transaksi [4].

\section{Return dan Resiko}

Hal mendasar dalam keputusan investasi adalah tingkat keuntungan yang diharapkan (return) dan resiko [9]. Return adalah hasil (tingkat pengembalian) yang diperoleh sebagai akibat dari investasi yang dilakukan. Ada beberapa jenis return yang biasa digunakan dalam perhitungan resiko, yaitu simple net return $\left(r_{t}\right)$ dan geometrik return atau log return $\left(R_{t}\right)$.

$$
\begin{gathered}
r_{t}=\frac{P_{t}-P_{t-1}}{P_{t-1}}=\frac{P_{t}}{P_{t-1}}-1 \\
R_{t}=\ln \left(\frac{P_{t}}{P_{t-1}}\right)=\ln \left(P_{t}\right)-\ln \left(P_{t-1}\right)
\end{gathered}
$$

Dimana:

\footnotetext{
$r_{t} \quad$ : simple net return pada periode $\mathrm{t}$

$R_{t} \quad:$ log return pada periode $\mathrm{t}$

$P_{t} \quad$ : nilai asset pada periode $\mathrm{t}$

$P_{t-1}$ : nilai asset pada periode t-1
} 
Dari persamaan (1) dan (2) dapat diperoleh hubungan log return dan simple net return, yaitu: $R_{t}=\ln \left(r_{t}+1\right)$. Jika terdapat $\mathrm{T}$ observasi, maka ekspetasi return yang diharapkan dapat dirumuskan sebagai berikut:

$$
E\left(R_{t}\right)=\bar{R}=\frac{\sum_{t=1}^{T} R_{t}}{T}
$$

Resiko (risk) adalah tingkat ketidakpastian akan terjadinya sesuatu atau tidak terwujudnya sesuatu tujuan, pada kurun atau periode waktu tertentu ${ }^{[1]}$. Salah satu alat pengukuran resiko yang sering digunakan adalah Value at Risk $(\mathrm{VaR})$.

\section{Value at Risk (VaR)}

Value at Risk ( $\mathrm{VaR})$ merupakan kerugian terbesar yang mungkin terjadi dalam rentang waktu/ periode tertentu yang diprediksi dengan tingkat kepercayaan tertentu [5]. Secara matematis, VaR dapat diformulasikan sebagai berikut:

$$
\operatorname{VaR}=P_{o} \cdot \sigma \cdot \alpha \cdot \sqrt{t}
$$

Dimana:

$P_{o} \quad$ : nilai asset atau nilai investasi awal

$\sigma \quad$ : estimasi nilai volatilitas

$\alpha \quad$ : tingkat signifikansi

$T \quad$ : holding periode

Setelah model diperoleh langkah selanjutnya adalah melakukan pengujian. Backtesting merupakan kegiatan membandingkan jumlah nilai VaR dengan nilai kerugian (actual loss) untuk mengetahui akurasi dari model. Jika nilai kerugian yang dihasilkan lebih besar dari nilai VaR, maka nilai tersebut mengalami overshoot. Selanjutnya untuk mengetahui suatu model VaR dapat dipakai atau tidak, maka dapat dilakukan uji validasi dengan menghitung nilai likelihood ratio (LR).

Berikut hipotesinya:

Ho : Model adalah Valid

$\mathrm{H} 1$ : Model adalah tidak Valid

Dengan statistik hitung:

$$
L R=-2 \log \left[(p *)^{x}(1-p *)^{n-x}\right]+2 \log \left[\left(\left(\frac{x}{n}\right)\right)^{x}\left(1-\left(\frac{x}{n}\right)\right)^{n-x}\right]
$$

Dimana:

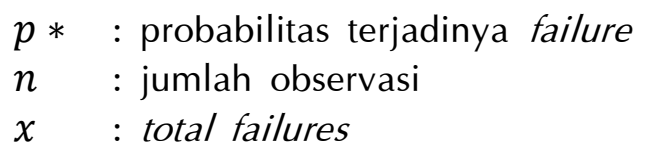

Selanjutya nilai LR dibandingkan dengan tabel Chi-Square $\left(\chi^{2}\right)$. Jika LR $>$ tabel Chi-Square, maka Ho ditolak atau model tidak valid.

\section{Analisis Data Time Series}

Timeseries adalah susunan observasi berurut menurut waktu, yang dinyatakan oleh $\mathrm{Z}_{1}, \mathrm{Z}_{2}, \mathrm{Z}_{3}, . ., \mathrm{Z}_{\mathrm{n}}$. Metode yang digunakan untuk menentukan model yang sesuai untuk data timeseries adalah Metode Box-Jenkins, model tersebut dikenal dengan model Autoregressive Moving Average (ARMA) untuk data stationer dan Autoregressive Integrated Moving Average (ARIMA) untuk data nonstationer [2], [3], [10].

1. Pemodelan untuk Mean

Pemodelan untuk mean dilakukan mengunakan model ARMA. Secara umum model ARMA(p,q) ditulis:

$$
Z_{t}=\varphi_{1} Z_{t-1}+\varphi_{2} Z_{t-2}+\cdots+\varphi_{p} Z_{t-p}+a_{t}+\theta_{1} a_{t-1}+\cdots+\theta_{q} a_{t-q}
$$


Jika $p=q=0$ maka model disebut White Noise (WN), jika $p=0$ maka model disebut Moving Average orde-q (MA(q)), dan jika $q=0$ disebut Autoregressive orde-p (AR(p)).

2. Pemodelan untuk Variance

Pemodelan untuk variance dilakukakan jika nilai residual bersifat heteroskedastisitas, sifat ini banyak dijumpai pada data keuangan. Kuadrat dari residual merupakan data yang digunakan untuk memodelkan variance, berikut disajikan beberapa model yang dapat digunakan untuk memodelkan variance:

- $\operatorname{GARCH}(p, q)$ :

$$
\begin{aligned}
& Z_{t}=x_{t}^{\prime} \beta+a_{t} \\
& h_{t}=\omega+\sum_{i=1}^{p} \alpha_{i} a_{t-i}^{2}+\sum_{i=1}^{p} \gamma_{i} h_{t-j}
\end{aligned}
$$

- GARCH-M (p,q):

$$
\begin{aligned}
& Z_{t}=x_{t}^{\prime} \beta+\delta h_{t}+a_{t} \\
& h_{t}=\omega+\sum_{i=1}^{q} \alpha_{i} a_{t-i}^{2}+\sum_{i=1}^{p} \gamma_{i} h_{t-j}
\end{aligned}
$$

- TARCH $(p, q, r)$ :

$$
\begin{aligned}
& Z_{t}=x_{t}^{\prime} \beta+a_{t} \\
& h_{t}=\omega+\sum_{i=1}^{q} \alpha_{i} a_{t-i}^{2}+\sum_{i=1}^{p} \gamma_{i} h_{t-j}+\sum_{k=1}^{r} \tau_{i} a_{t-i}^{2} d_{t-k}
\end{aligned}
$$

- TARCH-M $(p, q, r)$ :

$$
\begin{aligned}
& Z_{t}=x_{t}^{\prime} \beta+\delta h_{t}+a_{t} \\
& h_{t}=\omega+\sum_{i=1}^{p} \alpha_{i} a_{t-i}^{2}+\sum_{i=1}^{p} \gamma_{i} h_{t-j}+\sum_{k=1}^{r} \tau_{i} a_{t-i}^{2} d_{t-k}
\end{aligned}
$$

dimana : $d_{t}=\left\{\begin{array}{l}1, \text { jika } a_{t}<0 \\ 1, \text { jika } a_{t} \geq 0\end{array}\right.$

- $\operatorname{EGARCH}(p, q, r)$ :

$$
\begin{aligned}
& Z_{t}=x_{t}^{\prime} \beta+a_{t} \\
& \log \left(h_{t}\right)=\omega+\sum_{i=1}^{q} \alpha\left|\frac{a_{t-i}}{\sqrt{h_{t-i}}}\right|+\sum_{i=1}^{p} \gamma_{j} \log \left(h_{t-j}\right)+\sum_{k=1}^{r} \tau_{k} \frac{a_{t-k}}{\sqrt{h_{t-k}}}
\end{aligned}
$$

- EGARCH-M (p,q,r):

$$
\begin{aligned}
& Z_{t}=x_{t}^{\prime} \beta+\delta h_{t}+a_{t} \\
& \log \left(h_{t}\right)=\omega+\sum_{i=1}^{q} \alpha_{i}\left|\frac{a_{t-i}}{\sqrt{h_{t-i}}}\right|+\sum_{i=1}^{p} \gamma_{j} \log \left(h_{t-j}\right)+\sum_{k=1}^{r} \tau_{k} \frac{a_{t-k}}{\sqrt{h_{t-k}}}
\end{aligned}
$$

- $\operatorname{PARCH}(p, q)$ :

$$
\begin{aligned}
& Z_{t}=x_{t}^{\prime} \beta+a_{t} \\
& \sqrt{h_{t}^{\vartheta}}=\omega+\sum_{i=1}^{q} \alpha\left(\left|a_{t-i}\right|-\tau_{i} a_{t-i}\right)^{\vartheta}+\sum_{=1}^{p} \gamma_{j} \sqrt{h_{t-j}^{\vartheta}}
\end{aligned}
$$

- PARCH-M $(p, q)$ :

$$
\begin{aligned}
Z_{t} & =x_{t}^{\prime} \beta+\delta h_{t}+a_{t} \\
\sqrt{h_{t}^{\vartheta}} & =\omega+\sum_{i=1}^{q} \alpha_{i}\left(\left|a_{t-i}\right|-\tau_{i} a_{t-i}\right)^{\vartheta}+\sum_{=1}^{p} \gamma_{j} \sqrt{h_{t-j}^{\vartheta}}
\end{aligned}
$$

dimana :

$$
\vartheta>0,\left|\tau_{i}\right| \leq 1 \text { untuk } i=1,2, \ldots r \text {, }
$$




$$
\begin{gathered}
\tau_{i}=0 \text { untuk setiap } i>r \text { dan } r \leq q \\
\tau \neq 0 \text { merupakan effek asymmetric }
\end{gathered}
$$

\title{
Uji Efek ARCH (ARCH-LM)
}

Uji Autoregressive Conditional Heterokedasticity Lagrange Multiplier (ARCH-LM) dikembangkang oleh Engle [3], idenya adalah variansi residual bukan hanya merupakan fungsi independen tetapi tergantung dari residual kuadrat pada periode-periode sebelumnya.

$\mathrm{H}_{\mathrm{o}}: \alpha_{i}=0, \quad i=1,2, \ldots, q \quad$ (Tidak ada efek ARCH)

$\mathrm{H}_{1}$ : minimal ada satu $\alpha_{i} \neq 0$ (Terdapat efek $\mathrm{ARCH}$ )

Statistika uji:

$$
L M=(n-p) R^{2}
$$

Jika nilai $L M>\chi_{\alpha ; p}^{2}$ maka Ho ditolak atau tidak ada efek $\mathrm{ARCH}$

\section{Metode Penelitian}

\author{
Bahan (Data) \\ Sumber Data \\ : Data Penutupan Harian JII dari Januari 2009 - Juni 2011 \\ Peralatan \\ : Pojok Bursa Efek Indonesia \\ : 1 (satu) Unit Personal Computer \\ Software Excel 2007 dan Eviews 5.1 \\ Tempat Penelitian : Laboratorium Matematika Laboratorium Terpadu \\ UIN Sunan Kalijaga Yogyakarta
}

Metede Analisis Data :

Setelah data diperoleh langsung dilakukan analisis data, berikut berikut langkah-langkahnya:

1. Hitunglah nilai return, nilai return JII yang digunakan adalah logreturn

2. Lakukan uji stasioner data return JII untuk data pembentukan model, jika belum maka lakukan transformasi sampai data stationer, jika sudah ke langkah 3.

3. Lakukan uji normalitas, jika ya hitung nilai $\alpha=z$-score, jika tidak hitung nilai $\alpha$ menggunakan Cornish Fisher Expantion ()

4. Lakukan pemodelan untuk mean, yang dimulai dengan identifikasi model menggunakan plot ACF/ PACF, estimasi parameter setiap kandidat model, validasi model, sampai diperoleh model terbaik untuk model mean

5. Lakukan uji efek $\mathrm{ARCH}$ terhadap residual, jika ada maka lanjutkan ke langkah 6, jika tidak hitung nilai volatilitas dengan rumus standar deviasi dan ke langkah 8.

6. Lakukan pemodelan untuk variansi. Prosesnya sama dengan pemodelan mean, dimulai dengan identifikasi model, estimasi parameter, verifikasi model, sampai dengan pemilihan model terbaik untuk masing-masing model $\mathrm{CHT}$.

7. Hitung nilai volatilitas return $\mathrm{JII}$ untuk masing-masing model pada langkah 6.

8. Hitung nilai $V a R$ berdasarkan nilai yang diperoleh pada langkah 3 dan langkah 5 atau langkah 7

9. Lakukan uji validitas model-model VaR pada berbagai tingkat kepercayaan

10. Lakukan perbandingan nilai $V a R$ baik menggunakan data pembentukan model maupun data pengujian dari model untuk memperoleh model VaR yang terbaik

11. Implementasi atau penerapan dari model.

\section{Hasil Dan Pembahasan}

\section{Analisis Deskriptif}

Data awal yang digunakan dalam penelitian ini ada nilai indeks penutupan harian saham syariah yang diukur dengan Jakarta Islamic Index (JII) pasca krisis global 2008, yaitu dari Januari 2009 sampai dengan Juni 2011 dan dari nilai indeks tersebut dihitung nilai return saham syariah, nilai return yang 
digunakan adalah nilai logreturn (gambar 1), dan nilai return inilah yang akan digunakan untuk menganalisis resiko investasi saham syariah di BEl.

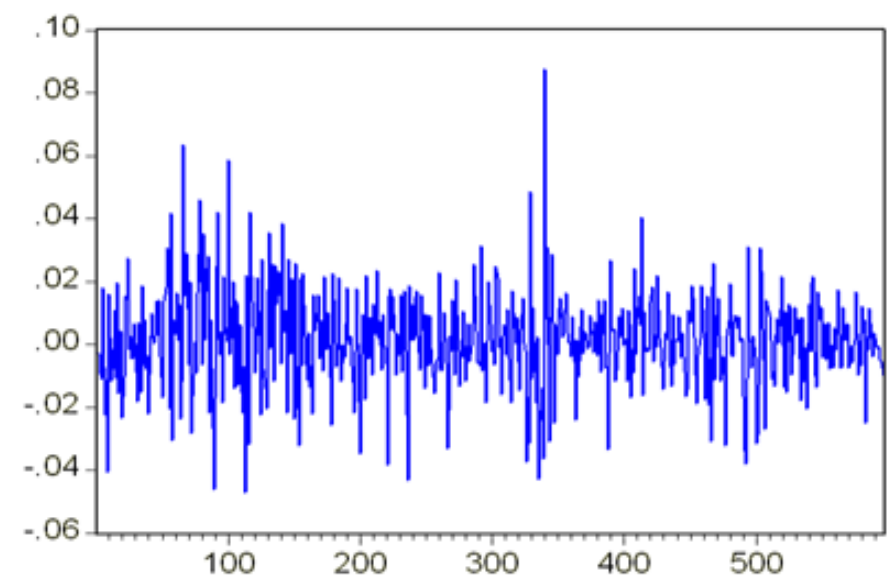

Gambar 1 Nilai Return Jakarta Islamic Index (JII) Januari 2009 - Juni 2011.

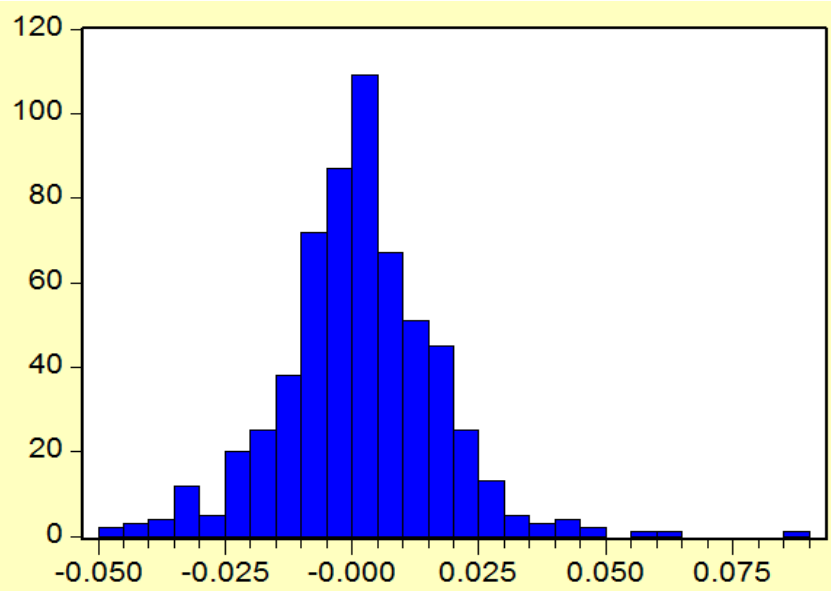

\begin{tabular}{|c|c|}
\hline \multicolumn{2}{|c|}{$\begin{array}{l}\text { Series: DLOGJII } \\
\text { Sample } 1596 \\
\text { Observations } 595\end{array}$} \\
\hline Mean & 0.001345 \\
\hline Median & 0.001202 \\
\hline Maximum & 0.087555 \\
\hline Minimum & -0.047117 \\
\hline Std. Dev. & 0.015415 \\
\hline Skewness & 0.291828 \\
\hline Kurtosis & 5.472746 \\
\hline Jarque-Be & 160.0334 \\
\hline Probability & 0.000000 \\
\hline
\end{tabular}

Gambar 2 Histogram, Statistik Deskriptif, dan Hasil Uji Normaitas Return JII.

Berdasarkan gambar 2, tampak bahwa return saham syariah pasca krisis global 2009 memiliki mean 0.001345 , standar deviasi 0,015415, skewness 0.291828, dan kurtosis 5.472746 . Nilai skewness bernilai positif (-) berarti bahwa distribusi data return cenderung miring ke kanan atau distribusinya mempunyai ekor yang lebih panjang ke kanan.

Terdapat 2 (dua) asumsi yang sangat perlu dilakukan dalam proses perhitungan nilai Value at Risk $(\mathrm{VaR})$ dengan pendekatan analisis timeseries, yaitu uji stationer dan uji normalitas. Uji stationer dilakukan karena asumsi awal yang yang harus dipenuhi dalam pemodelan timeseries adalah data harus stationer, sedangkan uji normalitas dangat diperlukan untuk menentukan nilai $\alpha$ dalam perhitungan nilai $\mathrm{VaR}$.

Tabel 1 Hasil Uji Asumsi Return JII.

\begin{tabular}{llll}
\hline Alat Uji Hipotesis & Statistik Hitung & Prob. & Keterangan \\
\hline ADF Test & -23.97555 & 0.0000 & Stationer \\
Jarque-Bera Test & 160.0334 & 0.0000 & Tidak Normal \\
\hline
\end{tabular}

Berdasarkan tabel 1, tampak bahwa data return saham syariah bersifat stationer tetapi berdistribusi tidak normal, sehingga nilai $\alpha=Z$-score tidak dapat digunakan secara langsung, sehingga nilai $\alpha$ dicari mengunakan Cornish Fisher Expansion. 
Dimana:

$$
\alpha=\alpha^{\prime}-\frac{1}{6}\left(\left(\alpha^{\prime}\right)^{2}-1\right) \xi
$$

$\alpha^{\prime} \quad$ : Z-score pada tingkat kepercayaan tertentu

$\xi \quad$ : koefisien skewness

Tabel 2 Nilai $\alpha$ Pada Berbagai Tingkat Kepercayaan 99\%.

\begin{tabular}{ccc}
\hline $\begin{array}{c}\text { Tingkat } \\
\text { Kepercayaan }\end{array}$ & Z-Score $\left(\alpha^{\prime}\right)$ & $\alpha$ \\
\hline $99.0 \%$ & 2.32667 & 2.111468 \\
\hline
\end{tabular}

\section{Pemodelan untuk Mean}

Langkah pertama yang dilakukan adalah membuat plot ACF/ PACF dari data return yang telah bersifat stationer untuk mengidentifikasi model dan diperoleh bahwa model yang paling cocok adalah White Noise (WN).

Berikut hasil estimasinya (tabel 3) dan tampak bahwa hasil estimasi signifikan pada tingkat kepercayaan 95\%, jadi model yang cocok untuk mean adalah model White Noise (WN).

Tabel 3 Estimasi parameter model kondisional mean.

\begin{tabular}{cccc}
\hline Model & Estimasi Paramater & Prob. & Keterangan \\
\hline White Noise & 0.001345 & 0.0338 & Signifikan \\
\hline
\end{tabular}

\section{Uji Heterokedastisita}

Untuk mendeteksi adanya heterokedasititas pada model mean (model WN) yang telah terbentuk di atas dapat mengunakan uji efek ARCH-LM dan memperhatikan plot ACF/ PACF residual kuadrat.

Pengujian efek ARCH:

Tabel 4 Hasil Uji Efek ARCH.

\begin{tabular}{cccc}
\hline ARCH Test & & & \\
\hline F-statistic & 6.096030 & Probability & 0.000142 \\
\hline Obs ${ }^{*}$-squared & 20.14908 & Probability & 0.000158 \\
\hline
\end{tabular}

Hipotesis

$$
\begin{array}{ll}
\mathrm{H}_{0}: k=0, k=1,2, . ., p . & \text { (tidak ada efek } \mathrm{ARCH}) \\
\mathrm{H}_{1}: \text { minimal ada satu } k \neq 0 & \text { (terdapat efek } \mathrm{ARCH} \text { ) }
\end{array}
$$

Statistik uji

$\mathrm{LM}=\mathrm{TR}^{2},(\mathrm{~T}=$ banyak residual atau banyak residual pada residual kuadrat $)$.

Pada tingkat signifikansi $=5 \%$, kriteria uji adalah tolak Ho jika probabilitas LM Test $<=5 \%$, karena Probabilitas $\mathrm{LM}=0.000158<=5 \%$, maka Ho ditolak berarti terdapat korelasi antara data residual kuadrat sampai lag ketiga atau terdapat efek ARCH. Sehingga perlu dilakukan memodelan untuk Variansi.

\section{Pemodelan Variansi}

Residual kuadrat merupakan dasar dalam menentukan variansi. Oleh karena itu koleogram (plot ACF dan PACF) dari residual kuadrat digunakan dalam menentukan apakah variansi dari data saling berkorelasi atau tidak. Residual kuadrat juga dapat digunakan untuk memprediksi orde model variansi dan diperoleh beberapa lag yang melewati garis Barlet, terutama pada lag ke-3. Hal ini berarti nilai terbesar $p$ dan $q$ adalah 3, sehingga untuk setiap model pendekatan masing-masing terdapat 15 (lima belas) sub model yang mungkin dan akan dipilih satu model terbaik berdasarkan nilai Bayesian 
Criterion Information (BIC) terkecil.Setelah dilakukan estimasi dan validasi pada tingkat kepercayaan 95\%, dari 16 (enam belas) pendekatan model yang digunakan, terdapat 10 (sepuluh) model signifikan (tabel 5) sedangkan 6 (enam) lainnya tidak terdapat model yang signifikan, yaitu TARCH, PARCH, EGARCH-M Variansi, PARCH-M Standar deviasi, PARCH-M Variansi, PARCH-M Log (Variansi).

Tabel 510 (Sepuluh) Pemodelan Variansi CHT yang Signifikan.

\begin{tabular}{|c|c|c|c|c|c|}
\hline \multirow[b]{2}{*}{ No } & \multirow[b]{2}{*}{ Model Pendekatan } & \multirow[b]{2}{*}{$\mathrm{BIC}$} & \multicolumn{3}{|c|}{ Validasi Model } \\
\hline & & & $\begin{array}{c}\text { No Efek } \\
\text { ARCH }\end{array}$ & Normal & $\begin{array}{c}\text { No } \\
\text { Autokorelasi }\end{array}$ \\
\hline 1 & $\operatorname{GARCH}(2,2)$ & -5.55942 & $\sqrt{ }$ & - & $\sqrt{ }$ \\
\hline 2 & $\operatorname{EGARCH}(3,0)$ & -5.55088 & $\sqrt{ }$ & - & $\sqrt{ }$ \\
\hline 3 & GARCH-M Standar deviasi $(1,1)$ & -5.57542 & $\sqrt{ }$ & - & $\sqrt{ }$ \\
\hline 4 & GARCH-M Variansi $(3,3)$ & -5.56623 & $\sqrt{ }$ & - & $\sqrt{ }$ \\
\hline 5 & GARCH-M Log(Variansi) $(1,1)$ & -5.57469 & $\sqrt{ }$ & - & $\sqrt{ }$ \\
\hline 6 & TARCH-M Standar Deviasi $(1,1)$ & -5.57357 & $\sqrt{ }$ & - & $\sqrt{ }$ \\
\hline 7 & TARCH-M Variansi $(1,1)$ & -5.57318 & $\sqrt{ }$ & - & $\sqrt{ }$ \\
\hline 8 & TARCH-M Log(Variansi) $(1,1)$ & -5.57346 & $\sqrt{ }$ & - & $\sqrt{ }$ \\
\hline 9 & EGARCH-M Standar Deviasi $(1,1)$ & -5.58617 & $\sqrt{ }$ & - & $\sqrt{ }$ \\
\hline 10 & EGARCH-M Log(Variansi) $(1,1)$ & -5.58526 & $\sqrt{ }$ & - & $\sqrt{ }$ \\
\hline
\end{tabular}

\section{Perhitungan dan Validasi Nilai VaR}

Dari 10 (sepuluh) model di atas, dilakukan perhitungan nilai VaR pada tingkat kepercayaan 99\% yang dilanjutkan validasi (becktesting) dengan LR test, berikut hasilnya:

Tabel 610 Hasil Perhitungan dan Validasi Nilai VaR.

\begin{tabular}{llccc}
\hline \multirow{2}{*}{ No } & \multirow{2}{*}{ Model Pendekatan } & \multirow{2}{*}{ Nilai VaR } & \multicolumn{2}{c}{ Validasi Model } \\
\cline { 3 - 5 } & & & Overshot & Valid \\
\hline 1 & GARCH $(2,2)$ & 0.032506 & 13 & $\sqrt{ }$ \\
2 & EGARCH $(3,0)$ & 0.032161 & 14 & - \\
3 & GARCH-M Standar deviasi $(1,1)$ & 0.032396 & 13 & $\sqrt{ }$ \\
4 & GARCH-M Variansi $(3,3)$ & 0.031812 & 15 & - \\
5 & GARCH-M Log(Variansi) $(1,1)$ & 0.033935 & 10 & $\sqrt{ }$ \\
6 & TARCH-M Standar Deviasi $(1,1)$ & 0.032264 & 14 & - \\
7 & TARCH-M Variansi $(1,1)$ & 0.032264 & 14 & - \\
8 & TARCH-M Log(Variansi) $(1,1)$ & 0.033583 & 11 & $\sqrt{ }$ \\
9 & EGARCH-M Standar Deviasi $(1,1)$ & 0.032051 & 15 & - \\
10 & EGARCH-M Log(Variansi) $(1,1)$ & 0.032912 & 13 & $\sqrt{ }$ \\
\hline
\end{tabular}

Berdasarkan tabel 6, tinggal 5 (lima) model pendekatan yang valid pada tingkat kepercayaan 99\%, yaitu EGARCH-M Log Variansi $(1,1)$, GARCH-M Standar Deviasi $(1,1)$, GARCH-M Log Variansi $(1,1)$, TARCH-M Log Variansi $(1,1)$, dan GARCH $(2,2)$. Dan dari 5 (lima) model tersebut yang memberikan nilai VaR terkecil adalah GARCH-M Standar Deviasi $(1,1)$ sebesar $3.2396 \%$. $3.2396 \%$ berarti pada tingkat kepercayaan 99\%, kerugian terbesar yang akan dialami investor yang melakukan investasi saham syariah adalah $3.2396 \%$ dari dana awal untuk setiap harinya.

\section{Kesimpulan}

Berikut adalah beberapa kesimpulan yang direkomendasikan dari penelitian ini adalah:

1. Dari 16 Model CHT yang digunakan dalam analisis resiko saham syariah dari Januari 2009-Juni 2011, terdapat 5 (lima) model yang valid pada tingkat kepercayaan 99\%, yaitu: GARCH-M Standar deviasi $(1,1)$, GARCH $(2,2)$, GARCH-M log Variansi $(1,1)$, EGARCH-M log Variansi $(1,1)$, dan TARCHM Log Variansi $(1,1)$ 
2. Dari kelima model tersebut model yang memberikan nilai VaR terkecil adalah GARCH-M Standar deviasi $(1,1)$ dengan nilai kerugian terbesar yang akan dialami investor pada tingkat kepercayaan $99 \%$ berturut-turut adalah 3,2396\% dari aset awal setiap harinya.

\section{Ucapan Terimakasih}

Peneliti mengucapkan terima kasih kepada Program Studi Matematika Fakutas Sains dan Teknologi UIN Sunan Kalijaga yang telah memberikan hibah penelitian dan Laboratorium Matematika Laboratorium Terpadu UIN Sunan Kalijaga sebagai tempat pelaksanaan penelitian, sehingga tulisan ini dapat diselesaikan. Penelitian ini dilakukan sejak Juli 2011 sampai Oktober 2011. Lokasi penelitian di kampus UIN Sunan Kalijaga (Suka) Yogyakarta.

\section{Referensi}

[1] Batuparan, D.S., 2000. BEI NEWS: Mengapa Risk Management? Edisi 4. Jakarta: Bursa Efek Indonesia (BEI)

[2] Enders, W. 1985. Applied Econometritcs Time Series. New York: John Willey \& Sons, Inc.

[3] Goyal, A., 2000. Predictability of Return Volatility from GARCH Models. UCLA: Anderson Graduate School of Management.

[4] Indonesia Stock Excange, 2010. Buku Panduan: Indeks Harga Saham Bursa Efek Indonesia 2010, Jakarta.

[5] Jorion, P., 2002. Value at Risk: The New Benchmark for Managing Financial Risk. McGraw-Hill, New York

[6] Kurniawan, T., 2008. Volatilitas Saham Syariah (Analisis atas Jakarta Islamic Index). KARIM Review Special Edition, January 2008.

[7] Qudratulah, M.F., 2010. Analisis Model Risiko Investasi Saham Syariah (Jakarta Islamic Index (JII)) mengunakan Value at Risk (VaR). Prosiding SNAST 2010 Teknologi IST AKPRIND Yogyakarta ISSN: 1979-911X. Hal: B-162 B-167.

[8] Sutungkir, H., \& Surya, Y., 2006. Value at Risk yang memperhatikan sifat statistika distribusi return. Munich Personal RePEc Archive (MPRA) paper.

[9] Tandelilin, E., 2001. Analisis Investasi dan Managemen Portofolio. Yogyakarta: BPFE.

[10] Wei, W.W.S., 1990. Time Series Analysis, Univariate and Multivariate Methods. Addison-Wesley Publishing Company, Inc. 